\title{
THE INFLUENCE OF THE SUBSTRATE ON THE TEMPERATURE GRADIENTS INDUCED BY PULSED LASER IRRADIATION OF THIN AMORPHOUS CrNi AND Cr FILMS
}

\author{
M. DINESCU and M. BIRJEGA \\ Institute of Atomic Physics, P.O. Box MG-6, Bucharest, Roumania
}

\begin{abstract}
We have reported /I-3/ TEM and TED results on the crystallization and oxidation of 20 to $80 \mathrm{~nm}$ thick amorphous CrNi and Cr films supported on EM copper grids submitted in air to the action of a single laser pulse $(\lambda=0.308 \mu \mathrm{m} ; \tau=20 \mathrm{nsec} ; \lambda=$ $0.6943 \mu \mathrm{m} ; \tau=60 \mathrm{nsec}$ and $400 \mu \mathrm{sec} ; \lambda=10,6 \mu \mathrm{m}, \tau=2.5 \mu \mathrm{sec})$. with intensities ranging from $0.03 \times 10^{6} \mathrm{~W} / \mathrm{cm}^{2}$ to $1 \times 10^{6} \mathrm{~W} / \mathrm{cm}^{2}$. In all our experiments /1-3/, we have found that the copper grid (meshes $0120 \mathrm{um}$ ) which support the $\mathrm{CrNi}$ or $\mathrm{Cr}$ thin films channel the incident laser beam so that at mesh level in the irradiated spot, temperature gradients develop from the center of the mesh towards its borders.

In this paoer, we are using the heat equation $/ 4,5 /$ in order to calculate the temperature induced to the film covering the copper grid and that induced to the supportless film. The calculations have revealed the thermal aradient that causes temperature to reach levels exceeding melting point in the center of the mesh, while keeping virtually at ambient values in the border area. To this aim, a model has been used allowing to calculate the energy absorbed into the film ( $C r N i$ or $C r$ ) for both the air-film-Cu and air-film-air situations $/ 4,5 /$ and for films thicknesses either exceeding the laser radiation penetration depth or comparable to it. Finally a discussion is introduced concerning the correlation of these calculations with the abovementioned along with new experimental results $/ 6,7 /$.
\end{abstract}

1. M. 1.Birjega, R.M.Bîrjega, C.A.Constantin, M.Dinescu, 1.Th. Florescu, I.N.Mihăilescu, N.Popescu-Pogrion, C. Särbu, Thin Solidfiims, $145(1986)$, 111 .

2. 1.Ursu, M. I.Bírjega, C.A.Constantin, M.Dinescu, I.N.Mihăilescu, N.Podescu-Pogrion, 1. Ketskemety, E.Szili, MRS Proc. Vo 1. 74,1986 .

3. 1.Ursu, M. I.Birjega, M.Dinescu, I. M.Mihăilescu, N.PopescuPogrion, L.Ribco, A.M.Prokhorov, V. l.Konov, V.N. Tokarev, Applied Surface Science 36 (1989), 640 .

4. W.W.Duley, Laser Processing and Analysis of Materials, Plenum Press, N.Y. London, 1982.

5. M.Born, E.Wolf, Principles of Optics, Pergamon Press, N.Y. $5-t h$ edition, 1981.

6. J.Solis, C.N.Afonso, and F.Catalina, Applied Surface Science $46(1990) 383$.

7. A. Jadin, I.V.Filic guine, M. Wautelet and L.D. Laude, $A p-$ plied Surface Science 46 (1990) 375. 